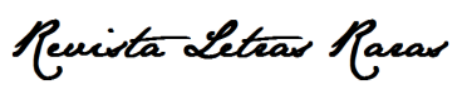

ISSN: $2317-2347$ - v. 6, n. 2 (2017)

\title{
Pequenos (des)compassos nas políticas linguísticas ${ }^{1}$ / Small disparities in language policy
}

Ina Emmel ${ }^{*}$

\section{RESUMO}

Essa análise se situa no âmbito conflituoso de compreensão das complexas implicações de políticas linguísticas que abrangem as grandes discussões atuais, a saber, a internacionalização das universidades, a corrente reformulação da base curricular nacional para a Educação Básica e o papel e a abrangência das línguas estrangeiras nessas instâncias, e também, as políticas que deveriam respeitar a formação identitária, no nosso caso a sul-brasileira, e, especificamente, junto à porta de acesso à Universidade - as LEs no vestibular. Os dados são de levantamentos feitos por volta de 2011 pela COPERVE e que permearam uma discussão sobre a manutenção (ou não!) da língua alemã e italiana (mas também o francês) no vestibular da UFSC. Questionam-se os argumentos que sustentavam sua eliminação e enfatizam-se razões para a sua manutenção, tendo por base, primordialmente, a pluralidade linguística alóctone sul-brasileira e a questão dos direitos linguísticos universais, e também dentro de uma perspectiva plural que é própria do mundo globalizado, de políticas de internacionalização. A discussão é amparada ainda por uma postura histórica da UFSC, que desde a sua fundação sempre promoveu instanciações plurilinguísticas, atendendo demandas provindas da sociedade. Entendemos que uma política linguística institucional deve se articular nessas instâncias diversificadas.

PALAVRAS-CHAVE: Política linguística. Vestibular UFSC. Línguas minoritárias. Internacionalização.

\section{ABSTRACT}

This paper aims to discuss the complex implications in educational environments related to linguistic politics which encompass actual discussions about globalization and the internationalization of universities, the current curricular reforms at primary and secondary levels, and the role and coverage of foreign languages in it, and also, those politics which respect identity formation in southern Brazil. More precisely, we will focus on the foreign languages offer in the entrance examinations to the university. The data, collected 2011 by COPERVE, intended to field a discussion about the maintenance (or not!) of languages like German, Italian and also French at the entrance exam to study at UFSC. We will analyze the arguments given by the central administration to eliminate those languages and emphasize reasons to continue to offer them. We sustain our point based on the linguistic plurality which still characterizes the South of Brazil, mainly following The Universal Declaration of Linguistic Rights and also taking into account the traditional plurilinguistic policies and the attendance of minority demands and inclusion policies which were always present along the history of our university. We assume that an institutional linguistic policy must necessarily articulate itself in those diverse environments.

KEYWORDS: Linguistic Politics. Vestibular UFSC. Minority Languages. Internationalization.

\section{Situando a discussão}

Alguns aspectos gerais sobre políticas linguísticas marcam o início da discussão que se pretende desenvolver no presente artigo, para, em seguida, focalizar o que acontece na Universidade Federal de Santa Catarina - UFSC em relação às situações linguísticas diversificadas presentes no âmbito de sua atuação e às possíveis mudanças que estão sendo discutidas em órgãos deliberativos da mesma, especificamente em relação às línguas do vestibular. Parte-se de uma concepção de que estamos diante de uma prática política e de que esta está atrelada a intervenções sobre situações concretas de uso e promoção de línguas. Se a política linguística é, segundo Calvet (2007, p. 86),

\footnotetext{
${ }^{1}$ Esse texto é uma versão atualizada e ampliada de Emmel (2011).

* Doutora em Teoria e Análise Linguística. Professora do Departamento de Língua e Literaturas Estrangeiras

(DLLE/UFSC). E-mail para contato: inaemmel@hotmail.com
} 


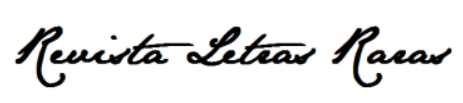

ISSN: $2317-2347$ - v. 6, n. 2 (2017)

“em última análise, da alçada dos decisores, nenhuma decisão pode ser tomada sem uma descrição precisa das situações (...)”. E o autor complementa: “e tampouco sem que se levem em consideração os sentimentos linguísticos, as relações que os falantes estabelecem com as línguas com as quais convivem (...)" (idem, ibidem). E, com base em Schiffman (1996), a política linguística que se pretende discutir aqui está fundamentada na cultura linguística, que abrange comportamentos, suposições, formas culturais, preconceitos, sistemas de crenças populares, atitudes, estereótipos, maneiras de pensar sobre a linguagem entre outros aspectos elencados pelo autor, todas associadas com uma determinada língua, e, no nosso caso, com determinadas línguas.

\section{Panorama geral}

Primeiramente, a verdadeira globalização deveria nos compelir a procurar uma integração sociolinguística verdadeira e profunda, aceitando todas as línguas sem restrição nenhuma, respeitando os direitos linguísticos plenos de todos os grupos, maiorias e minorias, tais como apregoados pela Declaração Universal dos Direitos Linguísticos, promulgada em julho de 1996. Outra instanciação relevante que estabelece esses direitos foi a Convenção de Proteção e Promoção da Diversidade das Expressões Culturais, adotada pela Conferência Geral da UNESCO em 2005, e ratificada pelo Brasil em 2007.

No percurso histórico do sistema educacional brasileiro, no entanto, observa-se sistematicamente uma falta de ações concretas articuladas com as definições legais quando se trata da inserção das línguas (estrangeiras) na grade escolar, chegando ao extremo de apenas se recomendar a sua inserção (como, por exemplo, no Parecer CFE 853/71 de 12 de novembro de 1971) e agora, em 2017, de ignorar completamente os pequenos passos dados no reconhecimento do papel e da importância das línguas minoritárias e recomendar a redução da oferta a uma língua estrangeira única, a saber, o inglês.

Em segundo lugar, cabe o registro de que no Brasil, apesar de devastador glotocídio em seus 500 anos de história, ainda existem, como é sabido, mais de 210 línguas, das quais 180 são autóctones (indígenas) e aproximadamente 30 são alóctones (de imigração), o que caracteriza o nosso país como naturalmente multilíngue. Além disso, "a história nos mostra", assim diz de Oliveira (2000, p.90), “que poderíamos ter sido um país ainda mais plurilíngue, não fossem as repetidas investidas do Estado (e das instituições aliadas, ou ainda a omissão de grande parte dos intelectuais) contra a diversidade cultural e linguística”. Ainda de acordo com de Oliveira (2007, p. 7), no prefácio da tradução para o português da obra de Calvet (2007), no Brasil, desde os tempos 


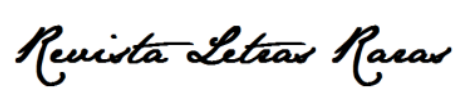

ISSN: $2317-2347$ - v. 6, n. 2 (2017)

coloniais, a ideologia da língua única talvez tenha camuflado essa realidade plurilíngue existente em nosso país, o que parece ter limitado as questões empíricas e teóricas levantadas pelos estudiosos das políticas linguísticas. Sabe-se, no entanto, que o sul do Brasil, contexto onde se inscreve a UFSC, é intensamente marcado por essa pluralidade linguística alóctone ainda nos dias atuais, um verdadeiro reservatório de potenciais falantes de línguas ditas minoritárias. ${ }^{2}$

\section{Reconhecimento das 'línguas brasileiras'}

Nesse sentido, vale lembrar que, desde 2006, está sendo elaborado o Livro das Línguas do Brasil (organizado pelo IPHAN - Instituto do Patrimônio Histórico e Artístico Nacional e o IPOL Instituto de Política Linguística, em conjunto com uma comissão da Câmara dos Deputados e do Congresso Nacional) $)^{3}$, para esse patrimônio cultural imaterial. Assim, não apenas se reconhece essa pluralidade, mas a mesma também passa a ser oficialmente registrada. No entanto, a reivindicação pelo direito a essas línguas, identificando nelas um papel e um lugar na sociedade, talvez, ainda continue sendo bastante tímido. Por pressões e de motivações até contraditórias, pequenos avanços feitos acabam por retroceder novamente.

Por outro lado, embora a Constituição de 1988 já conceda aos índios o direito às suas línguas, inclusive no aparato escolar, respectivamente através dos artigos 210 e 213, e também já regulamentado pela Lei de Diretrizes e Bases da Educação Nacional de 1996 (artigos 78 e 70) ${ }^{4}$, a extensão desses mesmos direitos às outras minorias linguísticas ainda não está devidamente institucionalizada e talvez nunca o seja. Já existem iniciativas bastante elaboradas nesse sentido, a saber, leis municipais que co-oficializam línguas minoritárias (MORELLO, 2015), projetos de educação bilíngue desde as séries iniciais, e até mesmo na educação infantil, principalmente nas fronteiras com países hispânicos, e igualmente em algumas escolas em comunidades de colonização germânica e italiana. Esses projetos, em sua maioria, são coordenados ou assessorados pelo IPOL, que por sua vez foi fundado e, por muitos anos, dirigido pelo Dr. Gilvan Müller de Oliveira, professor da UFSC (CCE/DLLV), especialista em política linguística, com reconhecimento nacional e internacional. Na contrapartida, agora mesmo, em 2017, pelo que indicam os últimos encaminhamentos de discussão sobre a Base Nacional Comum Curricular, tudo leva a crer que

\footnotetext{
${ }^{2}$ No caso específico do alemão, segundo Kaufmann (2003, p. 29), fora da Europa, não existe lugar no mundo com mais falantes dessa língua do que no sul do Brasil.

${ }^{3}$ Portarias IPHAN N ${ }^{\circ}$ 586, de 11 de dezembro de 2006 e IPHAN N ${ }^{\circ}$ 274, de 03 de setembro de 2007.

${ }^{4}$ Embora de Sousa e Afonso (2015, p. 29) mostrem "que a existência de direitos no plano normativo que asseguram uma educação bilíngue, intercultural e diferenciada não promove necessariamente o renascimento, a manutenção e a revitalização dessas línguas".
} 


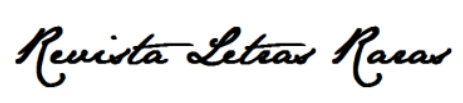

ISSN: $2317-2347$ - v. 6, n. 2 (2017)

novamente estamos retrocedendo nesse sentido ao se propor a hegemonia de uma língua única, o inglês. ${ }^{5}$

Em termos sul-brasileiros, como é sabido também, foi a integração com o MERCOSUL que ampliou marcadamente a contemplação do espanhol como língua estrangeira (LE) nas grades curriculares, o que se refletiu evidentemente em uma procura maior por essa língua, se comparado com o alemão, o francês e o italiano. O inglês, é claro, continua incólume em seu posto de língua franca, a preferência nacional como LE também em nossos currículos da educação básica e do ensino médio, tanto que, em 2017, novamente a discussão se volta para conceder unicamente a essa língua o espaço dentro desses documentos, ignorando os avanços, ainda que incipientes, que haviam sido feitos nas décadas anteriores. Os reflexos dessa imposição reducionista certamente serão sentidos na educação superior no que tange às licenciaturas em línguas estrangeiras (excetuando-se a de inglês), e que careceriam de uma discussão que foge ao escopo desse artigo. Em termos teóricos, no entanto, observa-se que parece estar em curso uma "política linguística" baseada em critérios até certo ponto essencialmente mercantilistas, dissociada dos tantos avanços que os debates teóricos da linguística aplicada acenavam terem alcançado.

\section{Contextualizando situações plurilíngues na UFSC}

A reivindicação para ampliação do leque de ofertas de línguas estrangeiras em nossos currículos escolares para além do inglês, e do espanhol até o presente momento, com o intuito primeiro de atender demandas internas das comunidades de formações identitárias não-lusas parece ter sido uma preocupação da UFSC desde a sua criação na década de 60. Primeiro por ter criado as licenciaturas para cinco diferentes línguas, formando mão-de-obra especializada capaz de atender a necessidades diferenciadas em termos linguísticos. E, em segundo lugar, por manter uma política de oferta diversificada de ensino de línguas estrangeiras em seu Colégio de Aplicação, possibilitando aos seus alunos do ensino de fundamental e médio a escolha entre quatro línguas estrangeiras (a saber: inglês, espanhol, francês e alemão).

Em um segundo momento, para exemplificar a participação ativa da UFSC na discussão específica em defesa e promoção das línguas de imigração mais representativas no sul do Brasil, houve um projeto piloto desenvolvido ao longo de quatro anos, durante a década de 80, em parceria

\footnotetext{
${ }^{5}$ Audiência pública para discussão do documento da Base Nacional Comum Curricular (http://cnebncc.mec.gov.br/). Obs.: até o momento da publicação deste artigo ainda não tinha sido disponibilizado o acesso oficial da documentação apresentada por parte da UFSC nesta audiência. No entanto, a autora participou da discussão do mesmo.
} 


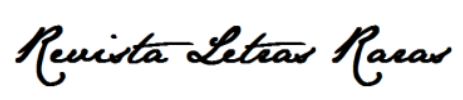

ISSN: 2317-2347 - v. 6, n. 2 (2017)

com a Secretaria de Educação do Estado de Santa Catarina, no contexto de reintrodução de línguas estrangeiras modernas nas escolas de SC, em atendimento às prerrogativas da LDB (Lei de Diretrizes e Bases) quanto a uma segunda língua estrangeira. Trata-se do projeto que proporcionou formação (em caráter emergencial) para professores de Língua Estrangeira atuantes nas mais diversas localidades de nosso Estado, e que, além disso, tinha também como objetivo proporcionar campo de trabalho para os licenciados, uma vez que a Secretaria acenava com a possibilidade de abertura de concursos públicos. A título de exemplo, em 1986, a UFSC habilitou em língua espanhola 61 professores da rede pública do Estado, atuantes nas cidades de Criciúma, Araranguá e Ibirama. A complementação em língua estrangeira somente foi oferecida em Língua Espanhola. As demais línguas, alemã e italiana, foram cumpridas na modalidade de Licenciatura Plena Única, como detalhado em seguida.

Passada mais uma década, percebeu-se que continuava existindo uma demanda local reprimida nas comunidades de colonização estrangeira em termos de oferecimento de línguas em todas as escolas e de pessoal especializado para assumir essa função. Além disso, como muitos desses professores de língua estrangeira já atuantes não tinham formação superior plena (uma exigência do Ministério da Educação) e não poderiam se deslocar para a capital para obtê-la, e aí nos parece mais interessante ainda, a UFSC novamente foi pioneira e montou outro grande projeto, dessa vez de formação superior plena extra-campus (Magister Letras - Alemão, Magister Letras Italiano), respectivamente, nas localidades de Jaraguá do Sul e Ibirama (para 2 turmas de 40 alunos de Licenciatura Letras-Alemão) e de Rodeio e Criciúma (para 2 turmas de 40 alunos de Licenciatura Letras-Italiano), respeitando as especificidades étnico-linguísticas de cada região dentro de SC.

A UFSC inovou igualmente com a introdução do Curso de Letras-LIBRAS, o primeiro do Brasil, o que demonstrou mais uma vez o quanto a nossa universidade está comprometida em atender o que preconiza a Declaração Universal dos Direitos Linguísticos, marcadamente para as minorias linguísticas. Este curso formou, desde a sua primeira turma graduada em 2010, tanto na modalidade EaD como presencial, mais de 750 licenciados (e outros tantos bacharéis).

Para não elencar apenas as instanciações de promoção de formação de professores de línguas consideradas minoritárias, a UFSC incentiva igualmente a formação universitária extracampus de professores de língua espanhola e inglesa. Em 2007, por exemplo, foi criado o curso Licenciatura Letras Espanhol, na modalidade a distância, o qual já formou 150 alunos e atualmente 


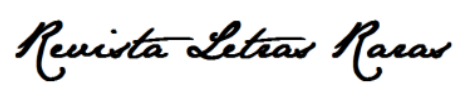

ISSN: 2317-2347 - v. 6, n. 2 (2017)

se encontra em sua terceira edição. Ainda em 2009 ofereceu o Curso de Letras Inglês - EaD, que também formou 150 alunos, conforme consta do site de Egressos-UFSC. ${ }^{6}$

Em linhas gerais, todas essas iniciativas da UFSC no contexto de formação de licenciados em línguas estrangeiras levam a crer que ela é uma universidade comprometida com a promoção de um plurilinguismo, respeitando um equilíbrio entre todas as línguas, administrando o status de cada uma delas nos diferentes contextos em que se insere a instituição, cumprindo, portanto, sua função social. $^{7}$

Mas, apesar de toda essa gama de atuação e contemplação das mais diversas línguas e em defesa delas, a gestão plena desse plurilinguismo parece estar diante de uma contradição quando inserida no debate em torno das línguas oferecidas no vestibular, onde se questionou a viabilidade de manutenção de todo o leque (alemão, francês, italiano, espanhol e inglês). Vamos retomar essa discussão aqui, ampliando o que já foi explorado em Emmel (2011) e atualizando algumas reflexões.

\section{As línguas no vestibular - releitura dos argumentos da UFSC}

Começamos com a retomada da análise dos documentos fornecidos pela Pró-Reitoria de Ensino de Graduação, em outubro de 2008, mostrando a oferta de línguas estrangeiras nos vestibulares de todas as universidades federais brasileiras, bem como um documento contendo os levantamentos estatísticos dos candidatos inscritos por língua nos vestibulares da UFSC nos oito anos antecedentes e que geraram o questionamento sobre a continuidade da oferta de línguas estrangeiras diversificadas nas provas do seu vestibular. Esses dados, evidentemente, são de domínio público e podiam ser acessados pelo site da universidade, no link da COPERVE (Comissão Permanente do Vestibular). Uma leitura mais apurada desses documentos, talvez com óculos especiais que nos são concedidos pela prática docente de línguas estrangeiras (no nosso caso é o alemão), atrelando isso a questões identitárias locais, bem como com certa familiarização com políticas linguísticas, talvez tenham nos autorizado a dimensionar mais detalhadamente as

\footnotetext{
${ }^{6}$ Dados obtidos no registro do CAGR/DAE/UFSC http://www.egressos.ufsc.br/ (acesso em 01/08/2017)

${ }^{7}$ A UFSC apresentou documento na Audiência Pública para discussão da Base Nacional Comum Curricular (BNCC), do dia 11 de agosto de 2017, promovida pelo Conselho Nacional de Educação (CNE/MEC) - Coordenadoria de Articulação de Formação Inicial e Continuada dos Profissionais da Educação Básica, no qual expressa o repúdio, por parte de discentes, professores e pesquisadores dos Cursos de Graduação em Letras Línguas Estrangeiras, ao total apagamento do plurilinguismo no documento da Base Nacional Comum Curricular.
} 


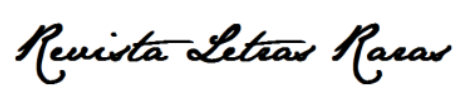

ISSN: 2317-2347 - v. 6, n. 2 (2017)

implicações de uma tomada de decisão dos órgãos centrais e gestores da universidade em propor uma redução dessa oferta para apenas o inglês e o espanhol.

Entre as universidades federais elencadas nos documentos disponibilizados pela COPERVE, observou-se que realmente poucas apresentavam opções de línguas estrangeiras em seus vestibulares que iam além do inglês, espanhol e francês. Mas eram exatamente as universidades federais mais representativas do Sul do Brasil que ofereciam também o alemão e o italiano (UFPR, UFRGS e a UFSC evidentemente). Parece-nos que a opção por essa oferta específica, especialmente nos vestibulares das universidades do Sul do Brasil, era coerente com as prerrogativas dos PCNs de então, que previam que, nos currículos escolares, a segunda língua estrangeira estivesse de acordo com as especificidades locais/regionais. No caso de Santa Catarina, certamente o italiano e o alemão fazem (ou deveriam fazer) parte deste leque. Desse modo, é possível dar a chance ao vestibulando de optar por uma língua com a qual ele se identifique mais, um direito que lhe é conferido pela Constituição Federal e pela Declaração Universal dos Direitos Linguísticos, mesmo que essa língua não atinja uma representatividade significativa em termos estatísticos (consequentemente, talvez, não justificável economicamente), se comparada com línguas como o inglês e o espanhol no universo de uma edição do vestibular.

No caso específico da UFSC, com a sua política de inclusão de minorias nos últimos vestibulares (sistema de cotas), o fato de, no seu vestibular de 2008, segundo os documentos analisados, apenas 1,28\% dos inscritos (394) terem optado pelas línguas alemão, francês ou italiano não deveria constituir uma minoria outra, para a qual os parâmetros de inclusão não deveriam valer. Os critérios de inclusão são outros, mas o que está por trás, certamente, não é.

Ademais, a UFSC oferece cinco licenciaturas em língua estrangeira moderna, um número bastante considerável e que vai ao encontro das demandas multiculturais e linguísticas que caracterizam o nosso país, bem como das tendências globais. Nesse sentido, a manutenção e mesmo a ampliação do leque de línguas oferecidas nas suas mais diferenciadas instâncias discursivas não deveriam ser limitadas logo no vestibular, que é, afinal, a porta de acesso, o seu cartão de visitas.

Por outro lado, e atualizando a atuação da nossa universidade, faz-se necessário registrar e enfatizar, que a UFSC participa ativamente do Programa IsF (Idiomas sem Fronteiras), desde as primeiras discussões para a sua criação e o seu lançamento oficial em dezembro de 2012, configurando-se, à época, apenas como Inglês sem Fronteiras. A universidade entendeu que o programa se constituía realmente em um terreno fértil para a formação inicial e continuada de professores, favorecendo parcerias e redes, incentivando a participação de seus professores enquanto especialistas, na gestão coletiva do programa. 


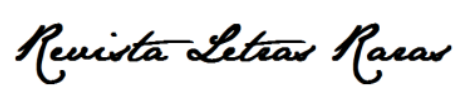

ISSN: 2317-2347 - v. 6, n. 2 (2017)

Portanto, para além da abrangência e visibilidade nacional e internacional que uma participação ativa no IsF confere às universidades que constituem esse programa, queremos destacar o papel da UFSC ao se articular localmente nas mais diversificadas áreas onde a questão linguística se configura como elemento fundante, e, especificamente para além das línguas já citadas, ampliou o leque de ofertas, por exemplo, de Japonês, Mandarim, Português para Estrangeiros e LIBRAS nos seus cursos extracurriculares, e no âmbito do Programa PET-Letras também para cinco línguas. E igualmente, numa visão globalizada e na direção da internacionalização da instituição, a UFSC faz isso por meio dos mais diversos intercâmbios multinacionais (ver listagem dos convênios institucionais na página da SINTER/UFSC: <http://sinter.ufsc.br/instituicoes-conveniadas/>) e igualmente nos convênios de negócios.

Mas o âmbito de atuação que consideramos mais importante é aquele permeado por questões identitárias, ou seja, na assessoria à formação de escolas bilíngues, no estreito relacionamento com o IPOL, na abertura de possibilidades de estágio para os seus licenciados em línguas estrangeiras, na oferta de licenciaturas em Letras à distância, principalmente a de Letras-LIBRAS com toda sua repercussão de inclusão. E, é claro, nossa participação na discussão e posicionamento crítico sobre alterações na base nacional curricular comum quando esta ignora as demandas e especificidades linguísticas regionais.

E, para conferir coerência a tudo o que foi elencado, entendemos que não pode ser justamente no vestibular que toda essa pluralidade deva ser restringida.

Para complementar as considerações, alguns aspectos de ordem mais prática: em uma das tabelas fornecidas pela COPERVE, aparecem as médias obtidas pelos alunos inscritos nas respectivas línguas estrangeiras em seu vestibular, mostrando que, nos oito anos antes de 2008, as médias alcançadas em alemão, italiano e francês superaram as obtidas em espanhol e inglês. A comissão responsável pelo levantamento estatístico sugere que isso talvez seja indício de uma possível vantagem aos candidatos que optam por essas línguas. Pensamos que as razões para tal deveriam ser melhor pesquisadas antes de se tomar uma decisão no sentido de eliminar essas línguas do vestibular pelo simples fato de parecer que o aluno que opta por elas leve vantagem em relação aos tantos que optam por inglês e espanhol. Se esse critério fosse válido, também poder-seia considerar uma vantagem para aqueles alunos que fizeram um Ensino Médio regular em relação àqueles que cursaram uma escola técnica, por exemplo, onde pouca ênfase é dada às ciências biológicas e da terra. Isso sem considerar o abismo de vantagens entre aqueles provindos de escolas públicas em relação àqueles que estudaram em escolas particulares. 


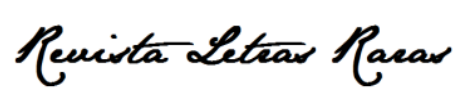

ISSN: $2317-2347$ - v. 6, n. 2 (2017)

Em outra tabela fornecida, aparecem os dados referentes às opções de língua estrangeira de vestibular dos inscritos nas habilitações em Letras Alemão, Letras Francês e Letras Italiano, novamente indicando que a opção pelas respectivas línguas é bastante baixa. No entanto, se pensarmos que o quesito língua específica não é nem exigido para os ingressantes nessas habilitações (basta ver os editais), esse argumento também não se sustenta. Novamente, nesse caso, poderíamos recorrer aos direitos constitucionais dos vestibulandos e à Declaração Universal dos Direitos Linguísticos, uma vez que a opção por querer estudar uma determinada língua, cursando um curso de Letras Estrangeiras, não está atrelada à condição de se valer de outra para conseguir ter acesso a isso. ${ }^{8}$

\section{Considerações Finais}

Acreditamos que os aspectos gerais apontados no começo deste texto em relação à importância do plurilinguismo em nível mundial e local (mais precisamente na UFSC) na atualidade, assim como as observações críticas feitas em relação aos documentos e a análise mais detalhada dos dados estatísticos fornecidos pela administração do vestibular da UFSC, constituem claras evidências de que a oferta das línguas alemã, italiana e francesa deva ser mantida no vestibular da UFSC, e, inclusive, ampliada.

Já a possibilidade de exposição desta argumentação também aqui poderá contribuir para que os colegas de outras universidades nas quais a oferta de línguas minoritárias ainda acontece nos seus respectivos vestibulares fiquem atentos para que propostas de aboli-las (que é, afinal, uma tendência inegável, e infelizmente parece estar associada principalmente a questões econômicas) ${ }^{9}$ não deixem de passar por uma discussão mais ampla, e sobretudo coerente, envolvendo nela não apenas os gestores universitários, mas sobretudo especialistas em política linguística institucional e pessoas comprometidas com os direitos linguísticos plenos da comunidade em geral. Na UFSC tivemos a chance de nos fazer ouvir no fórum deliberativo enquanto voz do Departamento de Língua e Literatura Estrangeiras e de todo o Centro de Comunicação e Expressão, juntamente com o Colégio de Aplicação, naquela oportunidade. Talvez, em um lance de pura sorte, cujos detalhes não cabem ser explorados aqui. Mas acreditamos que, uma vez que nos posicionamos enquanto departamento a favor da manutenção das línguas alemã e italiana (por razões identitárias, por terem

\footnotetext{
${ }^{8}$ No vestibular da UFSC exige-se que o candidato faça a opção, no momento da inscrição, por realizar a prova de língua estrangeira em uma das línguas ofertadas, independente do curso que queira cursar depois.

9 Em Santa Catarina, por exemplo, a ACAFE, fundação responsável pelo vestibular aplicado em 16 universidades e fundações universitárias catarinenses, em 2005, retirou de seu vestibular as línguas alemão, francês e italiano, sem qualquer consulta à comunidade, simplesmente alegando razões financeiras.
} 


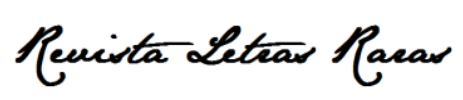

ISSN: $2317-2347$ - v. 6, n. 2 (2017)

um papel e um lugar inegável na sociedade catarinense e sul-brasileira) e também a francesa no nosso vestibular, nos tornamos visíveis e podemos contribuir, tanto em termos teóricos como políticos, para o desenrolar dessa discussão.

As considerações feitas, tendo como base analítica o exemplo das línguas estrangeiras no vestibular da UFSC, aparentemente sem tanta relevância diante de um espectro macro que aborda as grandes questões como a globalização, a internacionalização das universidades e a Base Nacional Comum Curricular, também são instâncias de política linguística que demandam coerência. Se por um lado, como afirmam Abreu-e-Lima e Moraes Filho (2016, p. 304), os especialistas de línguas estrangeiras têm trabalhado ao longo dos anos para sensibilizar o governo sobre a importância das línguas estrangeiras na formação dos brasileiros e na valorização delas no Ensino Básico e Superior e serem eles os articuladores da política linguística local dentro das IES, entendemos que também é papel desses especialistas se posicionarem diante das incoerências internas que indiretamente ligam essas instâncias discursivas.

Calvet (2007, p. 36) chama a atenção de que na política linguística há também política e que as intervenções na língua ou nas línguas têm um caráter eminentemente social e político. E ele nos lembra que "se as ciências raramente estão ao abrigo de contaminações ideológicas, a política e o planejamento linguístico não escapam à regra.” Valorizar o multilinguismo e multiculturalismo só é possível se considerarmos que a variante da língua escolhida é uma opção do cidadão e vai depender diretamente de suas preferências e/ou objetivos - e é esse também um dos princípios norteadores do programa IsF, conforme Sarmento, Abreu-e-Lima e Moraes Filho (2016, p. 306). Entendemos que algumas escolhas - que aparentemente pouca relação têm com o que classicamente entendemos por política linguística - podem sim disparar efeitos marcantes nos sentimentos linguísticos, nas relações que os falantes estabelecem com as línguas de seu convívio diário, na própria função das línguas. Existe, afinal, um laço estreito entre língua e sociedade.

\section{Referências}

ABREU-E-LIMA, D.M.; MORAES FILHO, W.B. O programa idiomas sem fronteiras. In: SARMENTO, S.; ABREU-E-LIMA, D.M.; MORAES FILHO, W.B. (Org.) Do Inglês sem Fronteiras ao Idioma sem Fronteiras - A construção de uma política linguística para a internacionalização. Belo Horizonte: Editora UFMG, 2016, p. 293-308.

BRASIL. Constituição da República Federativa do Brasil de 1988. Disponível em: <http://www.planalto.gov.br/ccivil_03/constituicao/constituicao.htm>. Acesso em: 01 ago. 2017. 


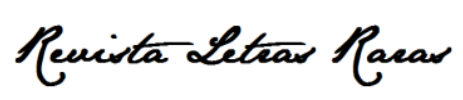

ISSN: $2317-2347$ - v. 6, n. 2 (2017)

BRASIL. DECRETO n 7.387, de 09 de dezembro de 2010 que institui o Inventário Nacional da Diversidade Linguística. Disponível em: <https://www.jusbrasil.com.br/topicos/26292008/artigo-8do-decreto-n-7387-de-09-de-dezembro-de-2010>. Acesso em: 01 ago. 2017.

BRASIL. LEI $\mathrm{n}^{\circ}$ 9.394, de 20 de dezembro de 1996 (LDB). Disponível em: <http://www.senado.gov.br/sf/legislacao/const/con1988/CON1988_05.10.1988/CON1988.htm> Acesso em: 07 out. 2011.

BRASIL. LEI $\mathrm{n}^{\mathrm{o}}$ 13.415, de 16 de fevereiro de 2017. Disponível em: <http://www2.camara.leg.br/legin/fed/lei/2017/lei-13415-16-fevereiro-2017-784336-normapl.html> Acesso em: 01 ago. 2017.

BRASIL. PARECER CFE 853/71, de 12 de novembro de 1971 do CFE. Núcleo-comum para os currículos do ensino de $1^{\circ}$ e $2^{\circ}$ graus. A doutrina do currículo na Lei n.5.692. In: Documenta n. ${ }^{\circ} 132$, Rio de Janeiro, nov. 1971.

CAGR/DAE/UFSC. Disponível em: <http://www.egressos.ufsc.br/ >. Acesso em: 01 ago. 2017.

CALVET, L.-J. As políticas linguísticas. Na Ponta da língua 17. Tradução: Duarte, I. O., Tenfen, J., Bagno, M. São Paulo: Parábola Editorial, 2007.

DECLARAÇÃO UNIVERSAL DOS DIREITOS LINGÜÍSTICOS. Disponível em: <http://www.unesco.pt/cgi-bin/cultura/docs/cul_doc.php?idd=14>. Acesso em: 07 out. 2011.

DE OLIVEIRA, G. M. Prefácio. In: CALVET, L.-J. As políticas linguísticas. São Paulo: Parábola Editorial, 2007, p.7-10.

DE OLIVEIRA, G. M. Brasileiro fala português: monolinguismo e preconceito linguístico. In: da SILVA, MOURA, H. M. de M. (org.) O direito à fala - A questão do preconceito linguístico. Florianópolis: Editora Insular, 2000, p.83-92.

DE SOUSA, S. C. T., AFONSO, M. A. V. Introdução para uma compreensão ampliada de Política Linguísticas. In: DE SOUSA, S. C. T., AFONSO, M. A. V. (org.) Políticas linguísticas declaradas, praticadas e percebidas. João Pessoa: Editora da UFPB, 2015, p.7-31.

EMMEL, I. Manutenção de línguas 'minoritárias' no vestibular da UFSC - um descompasso com as políticas linguísticas?. In: Anais Simpósio Internacional Linguagens e Culturas: homenagem aos 40 anos dos Programas de Pós-Graduação em Linguística, Literatura e Inglês da UFSC. Florianópolis: UFSC/CCE, 2011, p. 486-493.

KAUFMANN, G. Deutsch und Germanistik in Brasilien. In: Jahrbuch für Internationale Germanistik 35(1), Berlim/New York: DE GRUYTER, 2003, p.29-39.

MORELLO, R. O Brasil Multilíngue. In: MORELLO, R. (Org.) Leis e Línguas no Brasil. O processo de cooficialização e suas potencialidades. Florianópolis: IPOL, 2015, p.69-78.

SARMENTO, S.; ABREU-E-LIMA, D.M.; MORAES FILHO, W.B. (Org.) Do Inglês sem Fronteiras ao Idioma sem Fronteiras - A construção de uma política linguística para a internacionalização. Belo Horizonte: Editora UFMG, 2016.

SCHIFFMAN, H.F. Linguistic culture and language policy. London/New York: Routledge, 1996.

SINTER/UFSC. Disponível em: <http://sinter.ufsc.br/instituicoes-conveniadas/> Acesso em: 01 ago. 2017. 


\section{Revista Letear Racar}

ISSN: $2317-2347$ - v. 6, n. 2 (2017)

UNESCO. Convenção de Proteção e Promoção da Diversidade das Expressões Culturais Disponível em: <http://www.cultura.gov.br/politicas5//asset_publisher/WORBGxCla6bB/content/convencao-sobre-a-protecao-e-promocao-dadiversidade-das-expressoes-culturais/10913/> Acesso em: 01 ago. 2017.

Data de recebimento: $15 / 08 / 2017$

Data de aceite: $31 / 10 / 2017$ 